\title{
OPTIMAL HEATING AND ENERGY MANAGEMENT FOR SLABS IN A REHEATING FURNACE
}

\author{
Wei-Hsin Chen \\ Department of Greenergy, National University of Tainan, Tainan 700, Taiwan, R.O.C, weihsinchen@gmail.com \\ Mu-Rong Lin \\ Department of Aeronautics and Astronautics, National Cheng Kung University, Tainan 701, Taiwan, R.O.C \\ Tzong-Shyng Leu \\ Department of Aeronautics and Astronautics, National Cheng Kung University, Tainan 701, Taiwan, R.O.C
}

Follow this and additional works at: https://jmstt.ntou.edu.tw/journal

Part of the Electrical and Computer Engineering Commons

\section{Recommended Citation}

Chen, Wei-Hsin; Lin, Mu-Rong; and Leu, Tzong-Shyng (2010) "OPTIMAL HEATING AND ENERGY MANAGEMENT FOR SLABS IN A REHEATING FURNACE," Journal of Marine Science and Technology. Vol. 18: Iss. 1, Article 3.

DOI: 10.51400/2709-6998.1861

Available at: https://jmstt.ntou.edu.tw/journal/vol18/iss1/3

This Research Article is brought to you for free and open access by Journal of Marine Science and Technology. It has been accepted for inclusion in Journal of Marine Science and Technology by an authorized editor of Journal of Marine Science and Technology. 


\title{
OPTIMAL HEATING AND ENERGY MANAGEMENT FOR SLABS IN A REHEATING FURNACE
}

\author{
Wei-Hsin Chen*, Mu-Rong Lin**, and Tzong-Shyng Leu**
}

\begin{abstract}
Key words: slab optimal heating, reheating furnace, hot strip mill, energy consumption and management, iron and steel industry.
\end{abstract}

\begin{abstract}
Optimal heating for slabs in a reheating furnace is investigated numerically to aid in managing energy consumption of the reheating furnace in a hot strip mill, where an arctangent function is applied as the heating curve. Particular attention is paid to the relationship among the temperature uniformity, discharging target temperature and retention time of the slabs. The results indicate that the temperature difference between the slab surface and the core increases rapidly in the initial period and the maximum value of the temperature difference is close to the inflection point of the heating curve. After that, the internal temperature tends to be uniform. For a given retention time of slabs, it is difficult to simultaneously reach the requirements of discharging target temperature and desired temperature uniformity. A method to evaluate the optimal heating time is thus developed, using the Newton scheme. Some correlations linking the desired temperature uniformity and optimal heating time are established. They suggest that heating thinner slabs in the reheating furnace can facilitate employing energy more efficiently in contrast to heating thicker slabs.
\end{abstract}

\section{INTRODUCTION}

Hot strip mill is an important process in the iron and steel industry. The function of the hot strip mill is to roll slabs into hot rolled bands or coils by use of some specific facilities such as reheating furnaces, scalebreakers, roughing stands, coiler boxes, crop shears, finishing stands, run-out tables and downcoilers [3]. In order to achieve the goal of manufacturing coils, some important parameters such as slab temperatures, injection pressure of scalebreakers, rolling forces of roughing and

Paper submitted 02/13/08; accepted 12/26/08. Author for correspondence: Wei-Hsin Chen (e-mail: weihsinchen@gmail.com).

*Department of Greenergy, National University of Tainan, Tainan 700, Taiwan, R.O.C.

**Department of Aeronautics and Astronautics, National Cheng Kung University, Tainan 701, Taiwan, R.O.C. finishing stands, etc., have to be controlled precisely $[2,7,10$, $12,22]$. In these parameters, slab temperatures, including discharging temperature of a slab and its internal temperature distribution, play a crucial role in determining the quality of coils. This is because that the material deformation during rolling process, the forces and rolling loads of mills, as well as the performance of downcoilers are highly dependent on the slab temperatures which further determine energy consumption [17].

It is known that the material strength of a slab tends to decrease as the discharging temperature of the slab increases. In other words, the higher the discharging temperature of the slab leaves from the reheating furnace, the easier the roughing and finishing stands roll the slab [12]. Alternatively, when the temperature distribution inside a slab is regarded, a decrease in temperature difference in the slab is conducive to the rolling control of the mills. From the viewpoint of energy conservation, however, increasing discharging temperature of a slab means that more fuel is required to be burned for heating the slab. In addition, an improvement in temperature uniformity inside a slab implies that the retention time for the slab in a reheating furnace has to be elongated, thereby increasing energy consumption. This will emit more carbon dioxide and therefore enhance the atmospheric greenhouse effect $[4,8]$. Other drawbacks accompanying with higher discharging temperature or longer slab retention time include more scale produced [20], more cooling water required and higher risk of damaging rolling mills stemming from thermal stress and scale [16]. Consequently, a well-controlled slab temperature is closely relevant to energy utilization, rolling process and facilities maintenance.

It should be addressed that, despite wide use of hot strip mills in industry, most of the attention of the past studies concerning the hot strip mills were paid to the rolling force [2, $3,21]$, scale formation $[16,19,20]$ and material deformation $[10,18,22]$. In contrast, relatively little research was focused on the energy management of the reheating furnace. In the predictions of Chen et al. [7] relating fuel consumption in a reheating furnace, their results indicated that, with the conditions of fixed slab size and varying heating curve, increasing production rate of the furnace is conducive to utilizing fuel more efficiently. On the other hand, the study of Tsai and Chang [20] suggested that the parameters of view factor, emission factor, furnace temperature and the retention time of 


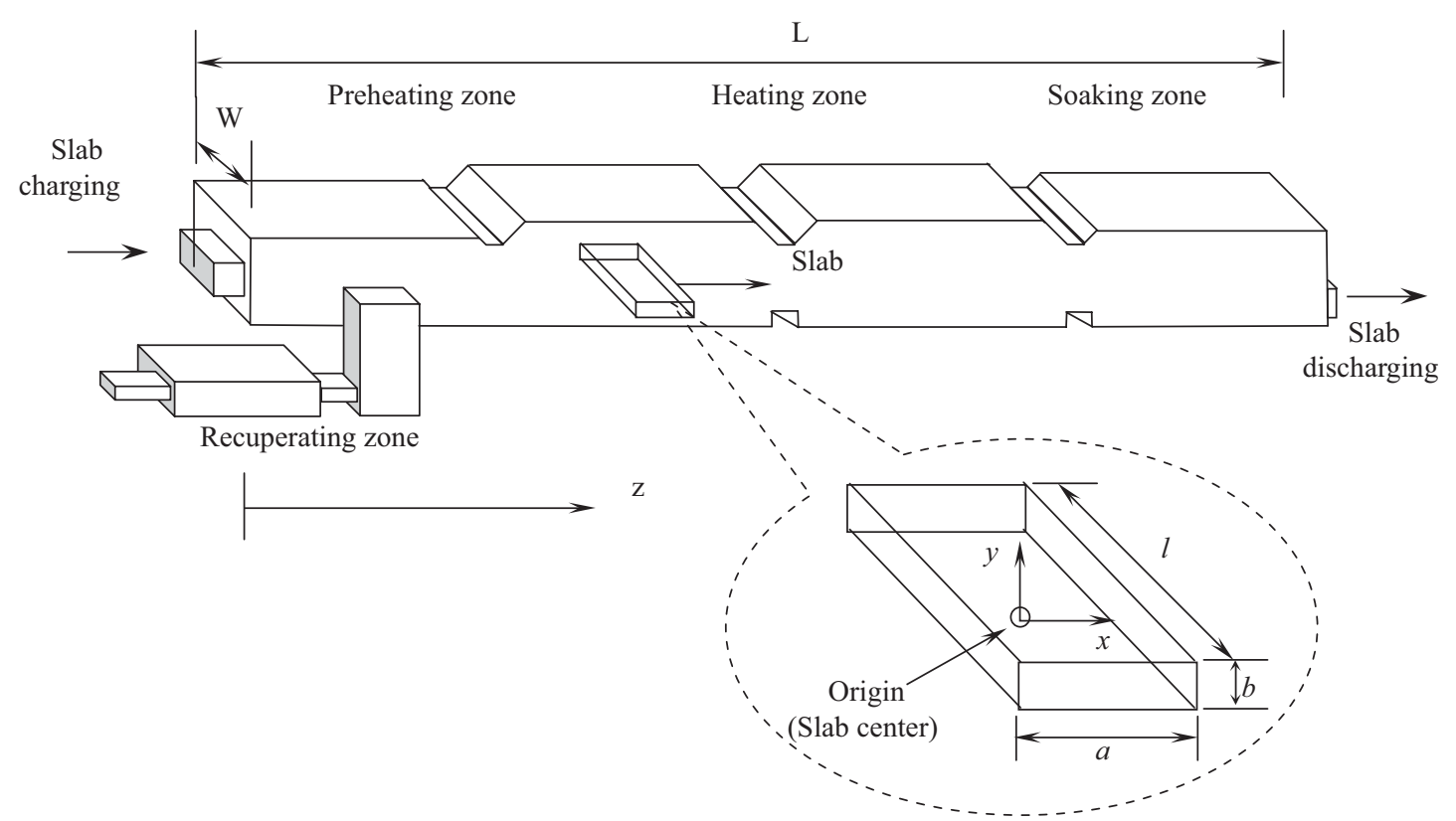

Fig. 1. Typical structure of a reheating furnace and coordinate system used in a slab.

slabs play an important role on the formation of scale and maintenance of the furnace, thereby influencing energy efficiency.

In order to recognize detailed heat transfer processes for slabs in a reheating furnace and to evaluate energy consumption situation of the reheating furnace, the present study is intended to evaluate temperature distribution in the slabs. Instead of the studies of varying heating pattern [7] or view factor [20], a typical heating curve of arctangent function will be considered. Furthermore, by varying slabs' width and gauge, a better operational process of the reheating furnace will be suggested to reduce fuel depletion.

\section{REHEATING FURNACE}

As far as a reheating furnace is concerned, as a whole, the structure of the furnace system can be divided into four different sections, consisting of recuperating zone, preheating zone, heating zone and soaking zone, as shown in Fig. 1. The functions of the four zones are described as follows:

(1) It is known that fuel consumption can be effectively reduced if waste heat is recovered to a great extent $[5,6]$. In a reheating furnace, in general, heat contained in hot flue gas is captured and absorbed by cold air in the recuperating zone, by means of heat exchange. That is to say, air used for fuel combustion in the furnace is preheated herein to reduce oil or natural gas depletion.

(2) After slabs are charged into the furnace, they are preheated in the preheating zone. The role of the preheating zone is to increase slabs temperature progressively. Therefore, with slabs marching the increment in the slabs surface temperature is controlled to be relatively slow.

(3) The slabs surface temperature rises rapidly after leaving the preheating zone. Accordingly, the majority of heat absorption by slabs is accomplished in the heating zone.

(4) When slabs stay in the soaking zone, the internal temperatures of the slabs are controlled as uniform as possible. Because of this, the temperature of this zone is progressively increased to the target or desired discharging temperature, similar to that of the preheating zone. Moreover, it is worthy of note that the staggered skids in the soaking zone are designed, which permit to largely decrease the skid marks and make the temperature in slabs more uniform.

Once a slab is sent into the reheating furnace, it will proceed from entrance, preheating zone, heating zone, soaking zone and to exit, sequentially. In the course of the slab's traveling, the slab surface temperature, which is controlled by the heating curve, with time and the retention time of the slab in the furnace determine the temperature uniformity. Furthermore, the heating curve and retention time will affect energy depletion or oil consumption. The surface temperature distribution is mainly governed by radiation and partially by convective and conductive heat transfer [11]. With the assumption of thermal equilibrium at the slab surface, the typical heating curve (or the slab's surface temperature) can be represented by an arctangent function. The surface temperature distribution $\left(T_{s}\right)$ with slab's location $(z)$ is plotted in Fig. 2 . in which the curve has been nondimensionalized and normalized in terms of charging temperature $\left(T_{c}\right)$, discharging temperature $\left(T_{d}\right)$ and furnace length $(L)$. 


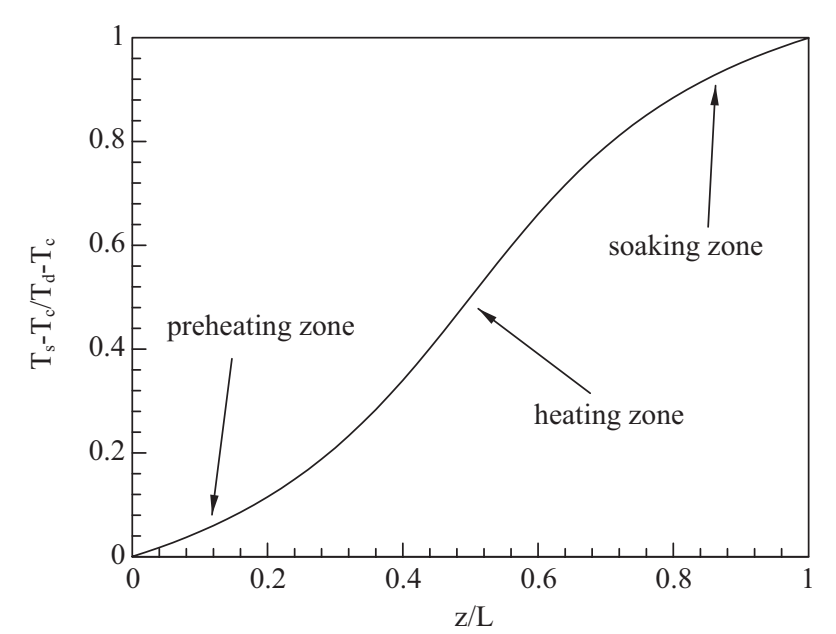

Fig. 2. Typical arctangent curve used for heating slabs in a reheating furnace.

$$
\begin{gathered}
\text { Heating curve: } T_{s}{ }^{\prime}=0.5+0.475 \operatorname{Arctan}\left[1.75\left(2 z^{\prime}-1\right)\right] \\
\text { where } \quad T_{s}{ }^{\prime}=\frac{T_{s}-T_{c}}{T_{d}-T_{c}} \quad \text { and } \quad z^{\prime}=\frac{z}{L}
\end{gathered}
$$

\section{MATHEMATICAL FORMULATION}

Typically, for a slab in a reheating furnace, the slab's length is large compared with its width and gauge. This implies, in turn, that heat transfer along the length direction almost plays no part in contributing temperature uniformity inside the slab. Therefore, it is proper to assume that heat transfer in the slab essentially pertains to two-dimensional behavior. Meanwhile, the effect of water cooled skids on the slab temperature is ignored in that the skid area is small when compared with the slab surface. Accordingly, the heat conduction or heat flow inside a slab can be described by a transient, two-dimensional diffusion equation. [9]

$$
\frac{\partial T}{\partial t}=\alpha\left(\frac{\partial^{2} T}{\partial x^{2}}+\frac{\partial^{2} T}{\partial y^{2}}\right)
$$

where $T, t$ and $\alpha$ are temperature, time and thermal diffusivity, respectively. The aforementioned equation is subject to the following initial and boundary conditions

Initial condition

$$
T(x, y, 0)=T_{c}
$$

Boundary conditions

$$
\begin{gathered}
T(a, y, t)=T(x, b, t)=T_{s} \\
\frac{\partial T(0, y, t)}{\partial x}=\frac{\partial T(x, 0, t)}{\partial y}=0
\end{gathered}
$$

where $a$ and $b$ stand for the width and gauge of the slab, respectively. The adopted coordinate system and slab size are also illustrated in Fig. 1 in which the origin is set at the slab center. It is assumed that temperature distribution in the slab is symmetric with respect to $x$ - and $y$-axis, no heat-flux boundary conditions are thus utilized along $x=0$ and $y=0$, as shown in (4). Subsequently, similar to the definition of the heating curve mentioned in Fig. 2, defining the following nondimensional parameters

$$
T^{\prime}=\frac{T-T_{c}}{T_{d}-T_{c}}, t^{\prime}=\frac{t \alpha}{a^{2}}, x^{\prime}=\frac{x}{a} \text { and } y^{\prime}=\frac{y}{a}
$$

and substituting them into (1) to (4) gives

$$
\frac{\partial T^{\prime}}{\partial t^{\prime}}=\frac{\partial^{2} T^{\prime}}{\partial x^{\prime 2}}+\frac{\partial^{2} T^{\prime}}{\partial y^{\prime 2}}
$$

Initial condition

$$
T^{\prime}\left(x^{\prime}, y^{\prime}, 0\right)=0
$$

Boundary conditions

$$
\begin{aligned}
& T^{\prime}\left(1, y^{\prime}, t^{\prime}\right)=T^{\prime}\left(x^{\prime}, b / a, t^{\prime}\right)=T_{s}^{\prime} \\
& \frac{\partial T^{\prime}\left(0, y^{\prime}, t^{\prime}\right)}{\partial x^{\prime}}=\frac{\partial T^{\prime}\left(x^{\prime}, 0, t^{\prime}\right)}{\partial y^{\prime}}=0
\end{aligned}
$$

An examination of the preceding equations indicates that the surface temperature of the slab is the function of time. Consequently, a numerical method was developed to predict heat transfer behavior in slabs and to analyze energy consumption characteristics of the reheating furnace. In the developed numerical method, in brief, the second order central difference and fully implicit schemes $[13,15]$ were adopted to discretize the diffusion equation. As a result, the discretized diffusion equation could be cast as

$$
\begin{aligned}
& \left(1+2 R_{x}+2 R_{y}\right) T_{m, n}^{j+1} \\
& \quad=R_{x} T_{m+1, n}^{j+1}+R_{x} T_{m-1, n}^{j+1}+R_{y} T_{m, n+1}^{j+1}+R_{y} T_{m, n-1}^{j+1}+T_{m, n}^{j}
\end{aligned}
$$

where $R_{x}=\Delta t^{\prime} / \Delta x^{\prime 2}$ and $R_{y}=\Delta t^{\prime} / \Delta y^{\prime 2}$. In the transient heating process, the entire period was divided into 50 time steps. When solving the discretization equations, on account of a large matrix encountered, an iterative procedure incorporating tridiagonal matrix algorithm was applied. Validation of the numerical method has been achieved previously [7] where it was revealed that the simulated result agreed well with the theoretical prediction. Moreover, three different grid systems of $21 \times 6,26 \times 10$ and $31 \times 12$ corresponding to $x$-direction 
and $y$-direction were tested. Because the predicted results based on the grid systems were almost the same, the first grid system was adopted. Accordingly, the adopted grid system and time step could satisfy the requirements of grid independence and computational accuracy.

When an optimal heating time is evaluated, it should be mentioned that, for a fixed-size slab with desired temperature uniformity, one extra boundary condition will be involved. The Newton scheme [1] is employed to solve the problem. That is, for the first two guessed heating times $t_{h, 1}$ and $t_{h, 2}$, the obtained discharging temperatures will be $T_{d, 1}$ and $T_{d, 2}$, respectively. Defining an error $e=T_{d, 1}-T_{d, 2}$ and assuming it is a monotonic function of heating time $t_{h}$, then a series of expansion of $e\left(t_{h}\right)$ from the obtained results gives

$$
e \cong e_{1}+\left(\frac{\partial e}{\partial t_{h}}\right)_{1} \Delta t_{h}=e_{1}+\left(\frac{\partial e}{\partial t_{h}}\right)_{1}\left(t_{h}-t_{h, 2}\right)
$$

If $e \rightarrow 0$, it yields

$$
t_{h}=-\frac{e_{1}}{\left(\partial e / \partial t_{h}\right)_{1}}+t_{h, 2}
$$

The new obtained heating time $t_{h}$ is then used as a new guessed heating time. The same procedure is reiterated until the convergence criterion is satisfied.

\section{RESULTS AND DISCUSSION}

In the present study, a low carbon steel with $0.05 \%$ carbon serves as the basis of investigation because this specific steel is frequently used in hot strip mills. With the low carbon steel, the thermal conductivity $(k)$, specific heat $(c)$, density $(\rho)$ and thermal diffusivity $(\alpha=\mathrm{k} / \rho \mathrm{c})$ are $70.8 \mathrm{~W} / \mathrm{m}^{\circ} \mathrm{C}, 0.4533 \mathrm{~kJ} / \mathrm{kg}^{\circ} \mathrm{C}$, $7891 \mathrm{~kg} / \mathrm{m}^{3}$ and $1.978 \times 10^{-5} \mathrm{~m}^{2} / \mathrm{s}$, respectively [14]. In the following discussion, the heat transfer characteristics inside slabs and energy consumption behavior of the reheating furnace will be investigated.

\section{Heat Transfer Inside a Slab}

Figure 3 first demonstrates the isothermal contours in a slab at three different heating times where the slab's width, gauge and retention time are $1250 \mathrm{~mm}, 250 \mathrm{~mm}$ and $200 \mathrm{~min}$, respectively. Moreover, the charging and discharging temperatures are set at $25^{\circ} \mathrm{C}$ and $1250^{\circ} \mathrm{C}$, respectively. When the time is $50 \mathrm{~min}$, Fig. 3(a) indicates that the slab surface temperature (or the maximum temperature) is around $219^{\circ} \mathrm{C}$, whereas the slab core temperature is about $185^{\circ} \mathrm{C}$. Physically, this difference represents the temperature gradient or driving force of heat transfer between the surface and the core. When the heating time reaches $100 \mathrm{~min}$, as shown in Fig. 3(b), the temperatures of the surface and the core are approximately
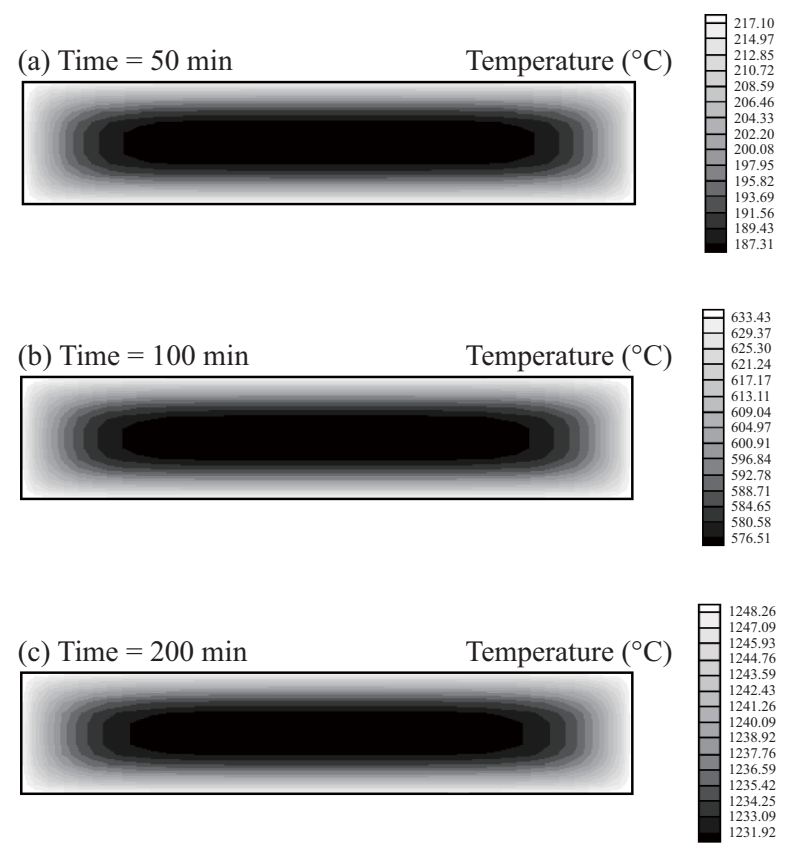

Fig. 3. Isothermal contours inside a slab at the heating times (a) $50 \mathrm{~min}$, (b) $150 \mathrm{~min}$ and (c) $250 \mathrm{~min}$.

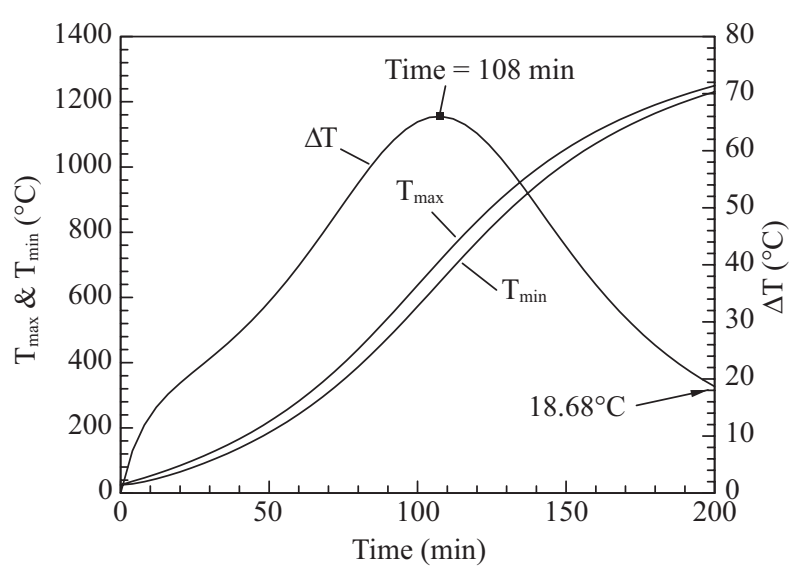

Fig. 4. Time variations of slab surface temperature $\left(T_{\max }\right)$, core tempeature $\left(T_{m i n}\right)$ and their difference $(\Delta T)$.

$637^{\circ} \mathrm{C}$ and $572^{\circ} \mathrm{C}$, respectively, revealing that the temperature gradient has been increased markedly. With the heating time marching to $200 \mathrm{~min}$, Fig. 3(c) depicts that the temperature difference has been decreased in a significant way, resulting from the maximum and the minimum temperatures being $1250^{\circ} \mathrm{C}$ and $1231^{\circ} \mathrm{C}$, respectively. On the other hand, Fig. 3 also suggests that the distances between the isothermal lines along $y$-direction are much shorter than that along $x$-direction (see Fig. 2); this illustrates that the majority of heat transferred into the core is carried out by the former.

The transient distributions of the maximum and the minimum temperatures as well as their difference $\Delta T$ (or temperature uniformity) versus the heating time are plotted in Fig. 4. It can be seen that as soon as the slab is charged into the 


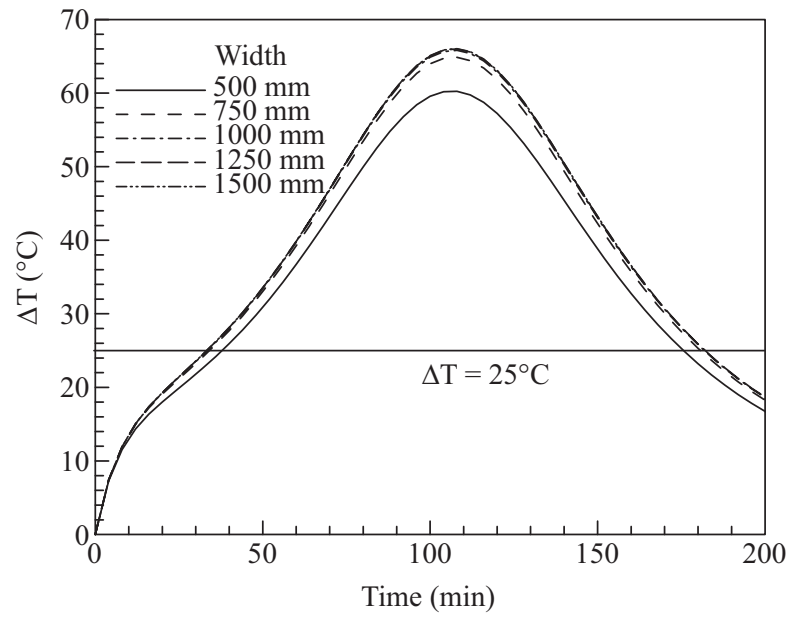

Fig. 5. Time variations of temperature uniformity in the slabs with various widths.

furnace, the temperature difference rises rapidly. This arises from the fact that the temperature increase on the slab surface is faster than in the core. The increasing tendency in $\Delta T$ persists until the time reaches $108 \mathrm{~min}$. It should be mentioned that the maximum point $\left(\Delta T=66^{\circ} \mathrm{C}\right)$ is close to the infection point of the heating curve (i.e., time $=100 \mathrm{~min}$ ). Mathematically, once the time passes through the inflection point of the heating curve, the increasing speed in the surface temperature tends to slow down, whereas the core temperature keeps growing. For this reason, the temperature difference turns to decline from the maximum point. The longer the heating time, the better the temperature uniformity in the slab, as observed in Fig. 4. When the slab arrives the exit, $\Delta T$ has decayed to $18.68^{\circ} \mathrm{C}$.

\section{Temperature Uniformity Inside Slabs}

It has been illustrated that the discharging temperature and temperature uniformity of a slab plays a vital role in the subsequent rolling processes. In Fig. 5, transient variations of temperature difference of the slabs at various widths are displayed. The slabs gauge is fixed at $250 \mathrm{~mm}$ and the retention time of the slabs in the furnace is $200 \mathrm{~min}$. It is evident that decreasing width will suppress the temperature difference. In other words, a narrower slab is conducive to promoting temperature uniformity, thereby facilitating the subsequent rolling processes. However, Fig. 5 also indicates that when the slab width is as wide as $1000 \mathrm{~mm}, \Delta T$ is almost independent of the variation of width, implying that heat transfer along $x$-direction nearly plays no part in contributing the core temperature. Though decreasing slab width enables a slab to reach the desired temperature uniformity earlier, it may lead to insufficient discharging temperature. Based on Fig. 5, Fig. 6 further presents the profiles of the heating time and discharging temperature of the preceding studied slabs under the condition of $\Delta T=25^{\circ} \mathrm{C}$ (i.e., the horizontal line shown in Fig. 5). For the lab width of $500 \mathrm{~mm}$, the target of $\Delta T=25^{\circ} \mathrm{C}$ is reached when

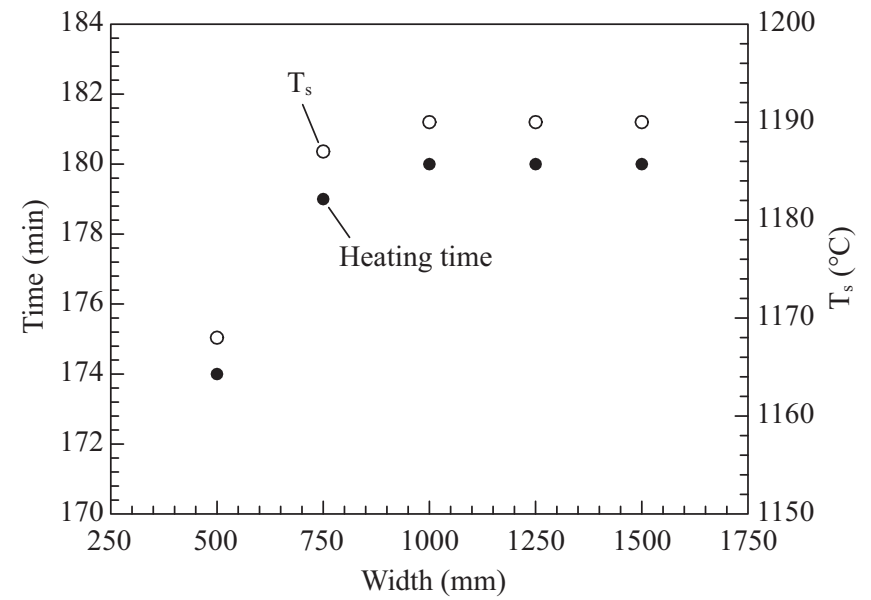

Fig. 6. Profiles of heating time and slab surface temperature under the condition of $\Delta T=25^{\circ} \mathrm{C}$.

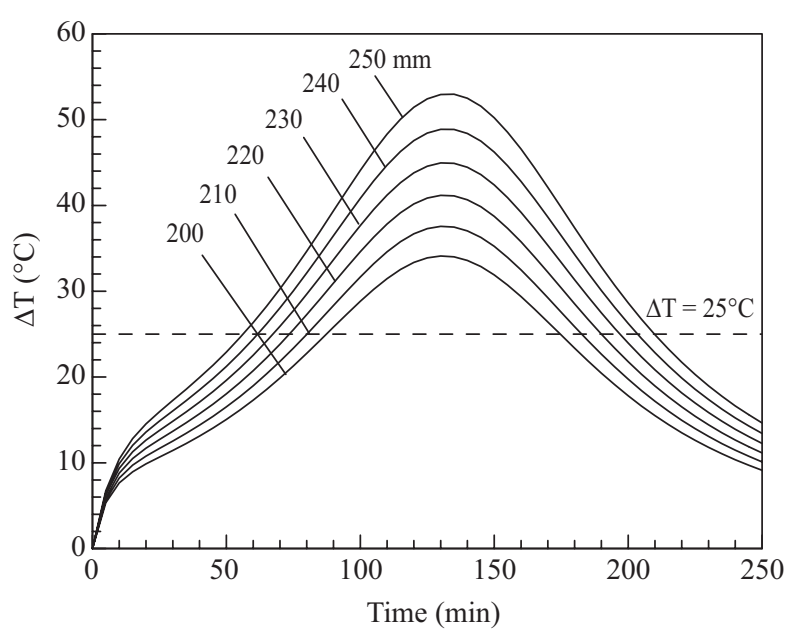

Fig. 7. Time variations of temperature uniformity in slabs with various gauges.

the heating time is $174 \mathrm{~min}$. However, the surface temperature at this moment is $1168^{\circ} \mathrm{C}$. In other words, if the slab is discharged at this instance, the entire temperature of the slab is too low to be rolled in a hot strip mill or more loading forces are needed to roll the slab. The same results also occur in the other slabs shown in Fig. 6.

Next, the influence of slab gauge on the variation of $\Delta T$ is examined in Fig. 7 where the slab width is specified at 1250 $\mathrm{mm}$ and the retention time is $250 \mathrm{~min}$. Unlike the effect of width shown in Fig. 5, varying gauge has a pronounced effect on the distribution of $\Delta T$, as a result of heat transfer controlled along $y$-direction. If we draw a horizontal line along $\Delta T=$ $25^{\circ} \mathrm{C}$, the heating times for the slabs reach this specified condition and their corresponding surface temperatures are provided in Fig. 8. For the slab gauge of $200 \mathrm{~mm}$, it is noted that only $172 \mathrm{~min}$ is needed if the desired temperature uniformity is satisfied. Unfortunately, the slab surface temperature is $979^{\circ} \mathrm{C}$ 


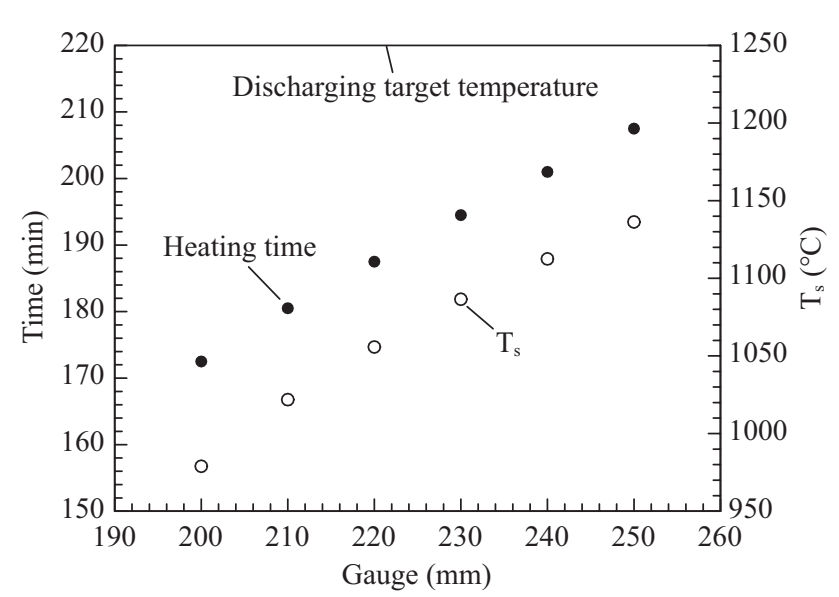

Fig. 8. Profiles of heating time and slab surface temperature under the condition of $\Delta T=25^{\circ} \mathrm{C}$.

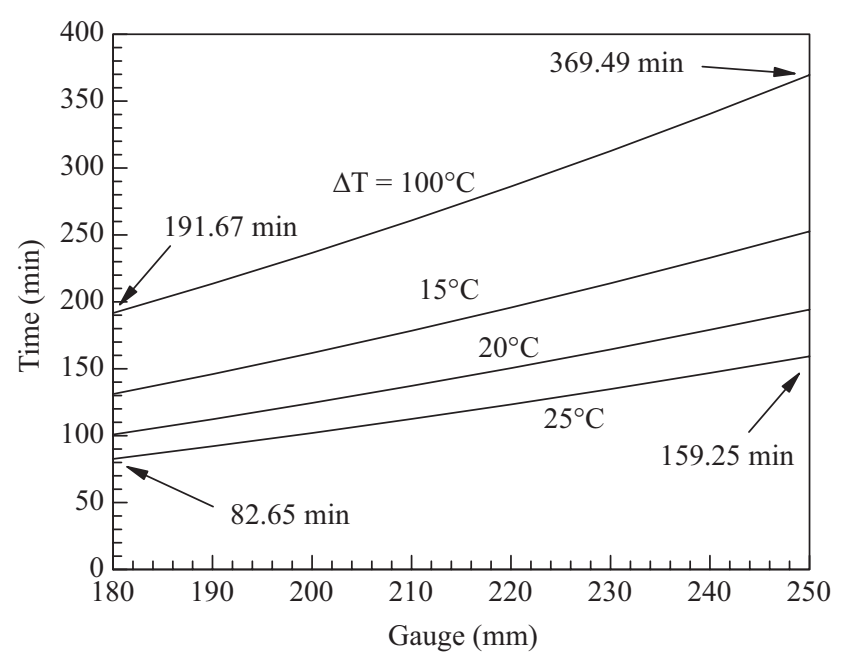

Fig. 9. Distributions of optimal heating time with respect to slab gauge under various desired temperature uniformities.

which is by far lower than the discharging target temperature $1250^{\circ} \mathrm{C}$. With increasing the slab gauge, both the heating time and surface temperature rise as well. But the surface temperatures are still much lower than the discharging target temperature, even though the slab gauge of $250 \mathrm{~mm}$ is encountered.

\section{Optimal Heating Time}

From the foregoing results, it illustrates that if the heating time is long enough, the demanded $\Delta T$ can be reached; however, the instantaneous surface temperature is much lower than the desired discharging temperature. Alternatively, if the discharging target temperature is satisfied when slabs arrive at the exit, the obtained temperature difference will be much lower than the desired one, rendering that the energy is not used efficiently. Consequently, an optimal heating time (or retention time) which simultaneously satisfies the requirements of

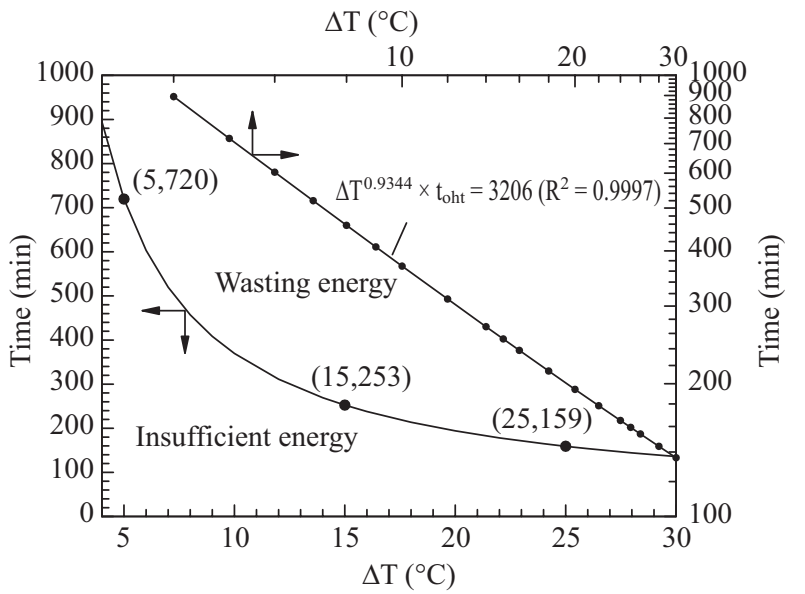

Fig. 10. A distribution of optimal heating time with respect to desired temperature uniformity and their correlation.

discharging target temperature and desired temperature uniformity should be applied. Figure 9 shows the distributions of the optimal heating time versus slab gauge at four desired temperature uniformities where the slabs' width is $1250 \mathrm{~mm}$. As mentioned previously, the Newton scheme will be used to overcome the numerical difficulty encountered. In the figure, a near linear relationship between the slab gauge and optimal heating time is obviously exhibited, whatever the desired temperature uniformity is. This arises from the fact that the heat transfer inside a slab is mainly determined along the gauge direction and the heat flux from the gas phase to the solid phase is inversely proportional to the slab gauge. With attention placed on the case of $\Delta T=25^{\circ} \mathrm{C}$, when the slab gauge is increased from $180 \mathrm{~mm}$ to $250 \mathrm{~mm}$ where the slab length and width are fixed, the production rate of the furnace will be increased by a factor of $1.39(=250 / 180)$. Nevertheless, time required to reach the specified uniformity will be elongated from $82.65 \mathrm{~min}$ to $159.25 \mathrm{~min}$. Because energy depletion for heating slabs is proportional to the slab's retention time, the preceding result implies that fuel consumption rate will be raised by a factor of $1.93(=159.25 / 82.65)$. For the case of $\Delta T=10^{\circ} \mathrm{C}$, the results are almost the same as that of $\Delta T=$ $25^{\circ} \mathrm{C}$. The increasing ratio in energy consumption rate is higher than that in furnace's production rate; it is recognized that heating thinner slabs in the reheating furnace is conducive to managing energy more effectively compared to heating thicker slabs.

Furthermore, a distribution of the optimal heating time with respect to the desired temperature uniformity is sketched in Fig. 10 where the slab's width and gauge are $1250 \mathrm{~mm}$ and $250 \mathrm{~mm}$, respectively. It reflects that the optimal heating time grows exponentially with decreasing the temperature difference. For instance, corresponding to $\Delta T=25^{\circ} \mathrm{C}, 15^{\circ} \mathrm{C}$ and $5^{\circ} \mathrm{C}$ the optimal heating times are $159 \mathrm{~min}, 253 \mathrm{~min}$ and 720 min, respectively. Above the curve it represents that extra energy is wasted, whereas under the curve it stands for the energy used for heating the slab is insufficient. The analysis 


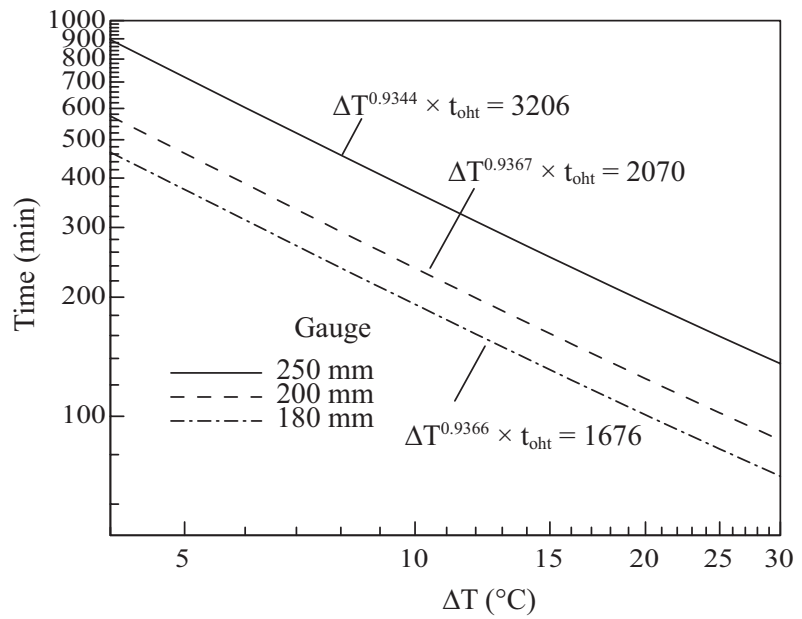

Fig. 11. Correlations of optimal heating time and desired temperature uniformity at various slab gauges.

elucidates that the relationship between $\Delta T$ and the optimal heating time $t_{\text {oht }}$ can be expressed by $\Delta T^{0.9344} \times t_{\text {oht }}=3206$ where $\mathrm{R}^{2}$ is 0.9997 and the units of $\Delta T$ and $t_{\text {oht }}$ are ${ }^{\circ} \mathrm{C}$ and minute, respectively. As a consequence, the smaller the desired temperature uniformity, much more energy will be needed for heating slabs. Theoretically, $t_{\text {oht }}$ will approach infinity when the desired temperature uniformity is close to 0 . This is because that $\Delta T=0$ is a singular point mathematically. In other words, it is impossible for slabs reaching the absolute uniformity in the reheating furnace. Similarly, for the slabs with gauges of $200 \mathrm{~mm}$ and $180 \mathrm{~mm}$, as shown in Fig. 11, the correlations can be written as $\Delta T^{0.9367} \times t_{\text {oht }}=2070$ and $\Delta T^{0.9366} \times t_{\text {oht }}=1676$, respectively. According to the aforementioned results, if a slab with gauge $250 \mathrm{~mm}$ are replaced by $180 \mathrm{~mm}$, though the production rate of the reheating furnace will be reduced approximately by $28 \%\left(=\frac{250-180}{250}\right)$, near $48 \%\left(=\frac{3206-1676}{3206}\right)$ of energy or fuel can be saved. It is thus concluded that rolling thinner slabs in a hot strip mill is a better energy management from the viewpoint of reheating furnace operation.

\section{CONCLUSIONS}

Slab heating in a reheating furnace has been investigated numerically to recognize the energy consumption characteristics of the furnace. When slabs are charged into the furnace, the temperature difference between the slab surface and the core climbs rapidly because of the nature of arctangent heating curve. After the heating time passes through the inflection point, the internal temperature in the slabs tends to be uniform. The current study indicates that, without using the optimal heating time, the desired temperature uniformity can be reached if the heating time is long enough. However, it may results in the insufficient discharging temperature. Alternatively, once the discharging target temperature is reached, the slabs internal temperature is too uniform so as to waste energy. Because both the discharging target temperature and desired temperature uniformity have a significant effect in the subsequently rolling processes, the optimal heating time (or retention time) for saving the energy of the furnace has been evaluated by employing the Newton scheme. Some correlations to link temperature uniformity and optimal heating time were established. Within the investigated range of slab gauge (180-250 $\mathrm{mm}$ ), it suggested that heating thinner slabs in the reheating furnace can use energy more efficiently in contrast to heating thicker slabs.

\section{NOMENCLATURE}

Slab width
Slab gauge
Specific heat
Thermal conductivity
Slab length
Furnace length
Time
Temperature
Furnace width
Abscissa in slab
Ordinate in slab
Distance from furnace entrance

\begin{tabular}{ll}
\multicolumn{2}{c}{ Greek Symbols } \\
$\alpha \alpha$ & Thermal diffusivity \\
$\rho$ & Slab density \\
$\triangle$ & Difference
\end{tabular}

\section{$\underline{\text { Superscripts }}$}

Dimensionless scale

$\begin{array}{lll}\text { Subscripts } & \\ d & \text { Charging } \\ d & \text { Discharging } \\ h & \text { Heating } \\ \text { oht } & \text { Optimal heating time } \\ s & \text { Slab surface }\end{array}$

\section{REFERENCES}

1. Allen, M. B. and Isaacson, E. L., Numerical Analysis for Applied Science, New York: Wiley, (1998).

2. Asada, H., Kitamura, A., Nishino, S., and Konish, M., "Adaptive and robust control method with estimation of rolling characteristics for looper angle control at hot strip mill," ISIJ International, Vol. 43, pp. 358-365 (2003).

3. Bhowal, P. and Mukherjee, S. K., "Modeling and simulation of hydraulic gap control system in a hot strip mill," ISIJ International, Vol. 36, pp. 553-562 (1996). 
4. Chen, W. H., "An analysis of gas absorption by a liquid aerosol in a stationary environment," Atmospheric Environment, Vol. 36, pp. 3671-3683 (2002).

5. Chen, W. H., "Waste burning and heat recovery characteristics of a mass burn incineration system," Journal of the Air \& Waste Management Association, Vol. 53, pp. 136-142 (2003).

6. Chen, W. H. and Chen, J. C., "Combustion characteristics and energy recovery of a small mass burn incinerator," International Communications in Heat and Mass Transfer, Vol. 28, pp. 299-310 (2001).

7. Chen, W. H., Chung, Y. C., and Liu, J. L., "Energy consumption analysis of reheating furnace in a hot strip mill," International Communications in Heat and Mass Transfer, Vol. 32, pp. 695-706 (2005).

8. Chen, W. H. and Lu, J. J., "Microphysics of atmospheric carbon dioxide uptake by a cloud droplet containing a solid nucleus," Journal of Geophysical Research - Atmospheres, Vol. 108, pp. 4470-4478 (2003).

9. Eckert, E. R. G. and Drake, R. M., Analysis of Heat and Mass Transfer, McGraw-Hill, New York (1972).

10. Han, H. N., Lee, J. K., Kim, H. J., and Jin Y. S., "A model for deformation, temperature and phase transformation behavior of steels on run-out table," Journal of Material Processing Technology, Vol. 128, pp. 216-225 (2002).

11. Han, S. H., Baek, S. W., Kang, S. H., and Kim, C. Y., "Numerical analysis of heating characteristics of a slab in a bench scale reheating furnace," International Journal of Heat and Mass Transfer, Vol. 50, pp. 2019-2023 (2007).

12. Laurinen, P. and Roning, J., "An adaptive neural network model for predicting the post roughing mill temperature of steel slabs in the reheating furnace," Journal of Material Processing Technology, Vol. 168, pp. 423-430 (2005).

13. Minkowycz, W. J. and Sparrow, E. M., Advanced Heat Transfer, Taylor \&
Francis, London (1997).

14. Ozisik, M. N., Heat Transfer: A Basic Approach, McGraw-Hill, New York (1985).

15. Patankar, S. V., Numerical Heat Transfer and Fluid Flow, Hemisphere, New York (1980).

16. Picqué, B., Bouchard, P. O., Montmitonnet, P., and Picard, M., "Mechanical behaviour of iron oxide scale: experimental and numerical study," Wear, Vol. 260, pp. 231-242 (2006).

17. Sakamoto, Y., Tonooka, Y., and Yanagisawa, Y., "Estimation of energy consumption for each process in the Japanese steel industry: a process analysis," Energy Conversion and Management, Vol. 40, pp. 1129-1140 (1999).

18. Siciliano, F. and Poliak, E. I., "Modeling of the resistance to hot deformation and the effects of microalloying in high-Al steels under industrial conditions," Materials Science Forum, Vol. 500-501, pp. 195-202 (2005).

19. Sun, W. H., Tieu, A. K., Jiang, Z. Y., Zhu, H. T., and Lu, C., "Oxide scales growth of low-carbon steel at high temperatures," Journal of Materials Processing Technology, Vol. 155, pp. 1300-1306 (2004).

20. Tsai, H. H. and Chang, S. M., "Improvement of fuel consumption and maintenance of heating furnace using a modified heating pattern," Journal of University of Science and Technology Beijing, Vol. 14, pp. 27-32 (2007).

21. Vergne, C., Boher, C., Gras, R., and Levaillant, C., "Influence of oxides on friction in hot rolling: Experimental investigations and tribological modeling," Wear, Vol. 260, pp. 957-975 (2006).

22. Watson, J. F., Rance, J. M., and Anderson, H. J., "Analysis of the fatigue failure of tee pieces forming part of a header in a descaling system in a hot strip rolling mill," International Journal of Pressure Vessels and Piping, Vol. 68, pp. 121-126 (1996). 